Article

\title{
Technical Approaches and Institutional Alignment to $100 \%$ Renewable Energy System Transition of Madeira Island-Electrification, Smart Energy and the Required Flexible Market Conditions
}

\author{
Hannah Mareike Marczinkowski ${ }^{1, *(D)}$ and Luísa Barros ${ }^{2}$ (D) \\ 1 Department of Planning, Aalborg University, Rendsburggade 14, 9000 Aalborg, Denmark \\ 2 ITI, LARSyS, University of Madeira, 9020-105 Funchal, Portugal; luisa.barros@iti.larsys.pt \\ * Correspondence: hmm@plan.aau.dk; Tel.: +45-93-56-23-55
}

Received: 30 June 2020; Accepted: 25 August 2020; Published: 27 August 2020

check for updates

\begin{abstract}
The integration of renewable energy (RE) in energy systems can be approached in many ways depending on local possibilities. Evaluating this in the limited context of islands, this paper presents a multi-energy system transition to a 100\% RE share in a two-folded technical analysis. The case study of Madeira Island using the EnergyPLAN modeling tool is used to show strengths and weaknesses of, on the one hand, electrifying all transport and heating demands on an island, while remaining demands are supplied with biomass, and, on the other hand, additional smart charging, vehicle-to-grid, thermal collectors and storages, as well as electrofuel production and storages. Technical results indicate the potentials and advantages of the second approach with $50 \%$ less biomass and no curtailment at 1-3\% higher costs, compared to the first one with $7 \%$ of production curtailed. The technical analysis is supported by the institutional analysis that highlights the balancing needs through additional flexibility and interaction in the energy system. For maximum flexibility, of both demand and grid, and successful implementation of $100 \%$ RE, investment incentives and dynamic tariffs are recommended entailing more dynamic consumer involvement and strategic energy planning.
\end{abstract}

Keywords: energy system analysis; modeling; multi-energy system; smart energy system; flexible demand; self-sufficiency; dynamic market

\section{Introduction}

Energy systems, both large and small, are transitioning towards higher shares of renewable energy (RE), such as from wind or photovoltaic (PV), in response to replacing fossil-fuel technologies in the fight against climate change [1]. A well-planned transition to $100 \% \mathrm{RE}$ is the main objective in many places however especially islands present challenging systems but also potential lighthouses in the struggle to analyze and identify the best approach to transitioning [2]. Not only are small and/or developing islands sensitive or even vulnerable in terms of access to energy at a reasonable cost [3], but also the importance and difficulties of various European islands was recognized in research [4], as well as politically in the "Valletta Declaration", which proclaims remote European islands as favorable for innovation [5]. Despite the differences in energy-intensity, population and geography, the common main energy objective is higher RE shares and self-sufficiency-for islands and globally.

The potential of transitioning to 100\% RE has been addressed on a global level by Ram et al. [6], as well as in a more detailed review by Hansen et al. [7]. Both present the trends and latest studies on $100 \%$ RE systems and how it has gained attention especially over the last few years. While some of the studies reviewed in [7] have included cross-border interaction in national energy systems, they are 
often made in island mode or are even focusing on geographical islands, which illustrates the role of island energy system perspectives. The increased shares of wind and PV often require balancing due to their fluctuations, such as through cross-border trade or storages. This is restricted in island systems since trade is often limited and storages not always available or feasible in island set-ups.

An extensive review related to this by Jurasz et al. [8] states that complementarity energetic studies are needed to evaluate the feasibility of variable RE. It shows that the design of energy management strategies and the balance between storage and cost of energy analysis can be used to increase the reliability of the system. The process of RE integration in a 100\% RE system at a regional level not only has to take into account historical data but also future consideration for different interested entities [8].

Various other studies and reviews have presented high RE utilization shares specifically on islands due to their vulnerability and often heavily fossil-reliant energy systems, but also due to the high RE potential. In [9], Kuang et al. review various islands on the way to or reaching a $100 \%$ RE share by evaluating different RE technologies and strategies for improvement. Ioannidis et al. [10] present the vulnerability and argue for the urgent need to transition energy systems of islands globally, while Cross et al. [11] further present potentials on islands and their importance in tests and demonstration-both including the need and possibilities of $100 \%$ RE island systems. Finally, Meza et al. present the complex transformation of a developing island with RE and storage capacity in competition with diesel for the existing generators and buses [12].

The integration of RE from wind and PV plays an important role, as the resource is naturally occurring and does not need to be traded or imported. While RE often supplies either the electricity or the heating sector, other sectors can benefit from using the renewable electricity and heat with further cross-sector integration as a required step to enable future smart energy systems and $100 \%$ RE in an efficient way. While [6,9-11] discuss the vulnerability and potential of RE on islands, their focus lies in the electricity sector, which is, however, already expanding across other sectors and is therefore required to be acknowledged differently. This cross-sector energy system planning-which is also known under the smart energy system (SES) label $[13,14]$ —addresses the intermittency of RE through the integration of electricity, heating and/or transport sectors to provide the best integration flexibility and maximize the impact of smart balancing technologies. This flexibility option is also referred to as multi-energy system interaction, where different energy sectors support each other, such as in [15] where the power to heat potential is presented. The otherwise often used approach of cross-border trade is not always an option for many islands, where self-sufficiency should be targeted instead. Additionally, without smart energy planning, a high use of biomass in the power plants can be the result, as this is one of the primary storable RE sources that can be stored and used directly [16]. However, using high amounts of biomass is seen critically under the energy-food nexus and should be limited to stay within locally sustainable levels [17].

Originating from the combined heat and power production experience in Northern Europe, heat and electricity have already been widely researched together, as has also been done in island perspective by comparing thermal storage and electrical batteries in two different islands [18]. Other examples of island studies using this approach have modeled isolated islands in the Azores [19], a small connected island in Croatia [20] or a large one in the Canary Islands [21]. All these articles discuss the technical and socioeconomic benefits of integrating energy sectors in the transition to $100 \%$ RE systems by making use of additional balancing and storage options.

While the research and the presented barriers in this transition are often solely technical and sometimes include socioeconomic aspects, the institutional conditions also need to be aligned to support the ever-increasing complexity of energy system planning. Similarly, concerning the integration of sectors towards a SES and required changes in the technical aspects, the market also needs to align with this transformation. The change of cost structures with increasing RE shares from, e.g., wind and $\mathrm{PV}$ is already widely discussed for the electricity market at the national level [22,23]. Based on the idea of SES, markets are suggested to be aligned in a 'smart way' through the concept of smart energy markets, where several sectors are technically and institutionally aligned [24]. The ongoing transition 
of the electricity market would benefit from considering the other sectors as their influence on each other is ever-increasing, not only technically. Existing literature, however, often includes cross-border options as well as gas infrastructure for this, which is limited in island energy systems. The design of market structures in isolated energy systems may be planned differently.

As islands present not only technically but also economically sensitive systems, this alignment of markets to support each other plays an important role in successfully transitioning to $100 \%$ RE shares. Here especially, strategic coordination of local barriers and potentials could benefit the demand as well as the supply side. Cuesta et al. [25] argue that RE analyses in small communities can be optimized by including social parameters to make the most out of the local RE resources. Similarly, local energy markets have been proposed to include multiple decentral energy sources and bidding structures to unlock local flexibility [26]. However, this previous research built upon the expansion of local district heating and neither in the newly recommended SES nor in an island context. These contextual considerations, however, should go hand in hand with the technical analyses.

Lund proposes to align the different technologies, social aspects and markets in the transition, especially if it includes radical change, which denotes situations that "involve change in existing organisations and institutions" [13]. With the limitations and potentials, aiming for $100 \%$ RE supply in a smart island energy system can be considered a radical change. An approach on how to govern such radical changes is suggested by Hvelplund and Djørup [27], who conclude that the organizational coordination of a $100 \%$ RE system requires a more active and communicative governance that coordinates the local technologies and demands. In line with this, the European Commission proposes an integrated energy market through preparedness on all levels, where the consumers are in the centre of the transition, making them an involved, stabilizing part of the market [28]. Despite acknowledging regional possibilities, islands have been mostly overlooked in the existing research and policies, even though the alignment of technologies and markets is most fragile and eminent here and may even present solutions useful in other geographical contexts.

The trends of aiming at $100 \%$ RE supply in either the separate sectors or cross-sectorally can be considered radical in any energy system, and the required alignment of technical, socioeconomic and institutional aspects has not been made for island energy systems. An example of islands evaluating different options to reach a SES with $100 \%$ RE share is through "smart technologies" in the Horizon 2020 project SMILE (smart island energy systems) [29], where technical and socioeconomic aspects have been introduced [2,30], but investigations into the institutional setup are still lacking behind. Smart technologies, such as smart charging and vehicle to grid (V2G), flexible electrofuel production or smart heating controls and storages, bring new aspects to the energy system and should be evaluated in the context of RE integration.

This article is filling the research gap for a case study, where both technical and institutional aspects are considered to integrate renewables and further reach a $100 \% \mathrm{RE}$ share. As existing literature approaches this only to some extent, usually separate and either with a sole focus on electrification or on the whole SES, both aspects are presented in parallel in this article. Besides a comparison of technical and socioeconomic options and results through a sociotechnical analysis, the market perspective is addressed in the particular setting of an island, where local energy market barriers are identified and the potential is presented. By illustrating the required institutional setup in alliance with the technical analysis of RE and novel technologies, the paper achieves a novel angle of research.

The case study to test this novelty aims at looking at an existing energy system and its current technologies and market, and how it can be optimized to reach a $100 \%$ RE share. One of the demonstration islands from SMILE is therefore chosen, namely Madeira Island, as an exemplary isolated energy system with its own local government and in high demand of a smart and institutionally sound energy system. Hence, this research may address islands, and particularly non-interconnected ones, but also other remote and rural energy systems can benefit from it to make better use of locally produced energy. 
In this paper, both technical scenarios and institutional comparisons are made to which the methodology can be found in Section 2. The corresponding results and recommendations are presented in the technical analysis in Section 3 and the market analysis in Section 4, before a discussion of both is made in Section 5. Section 6 concludes the whole paper briefly.

\section{Methodology}

This section introduces the methods and underlying procedures for the conducted analysis as well as the used data, which can be found in the Supplementary Material Section. This includes the use and creation of scenarios, details of the case study and the required steps to reach $100 \%$ RE systems in the technical analysis. A simplified overview of the steps and corresponding scenarios explained in Section 2.1 is illustrated in Figure 1. The modeling software EnergyPLAN that is used for these is introduced in Section 2.2. The final consequential step after the technical analysis is presented in the market analysis in Section 2.3 to support the scenarios.

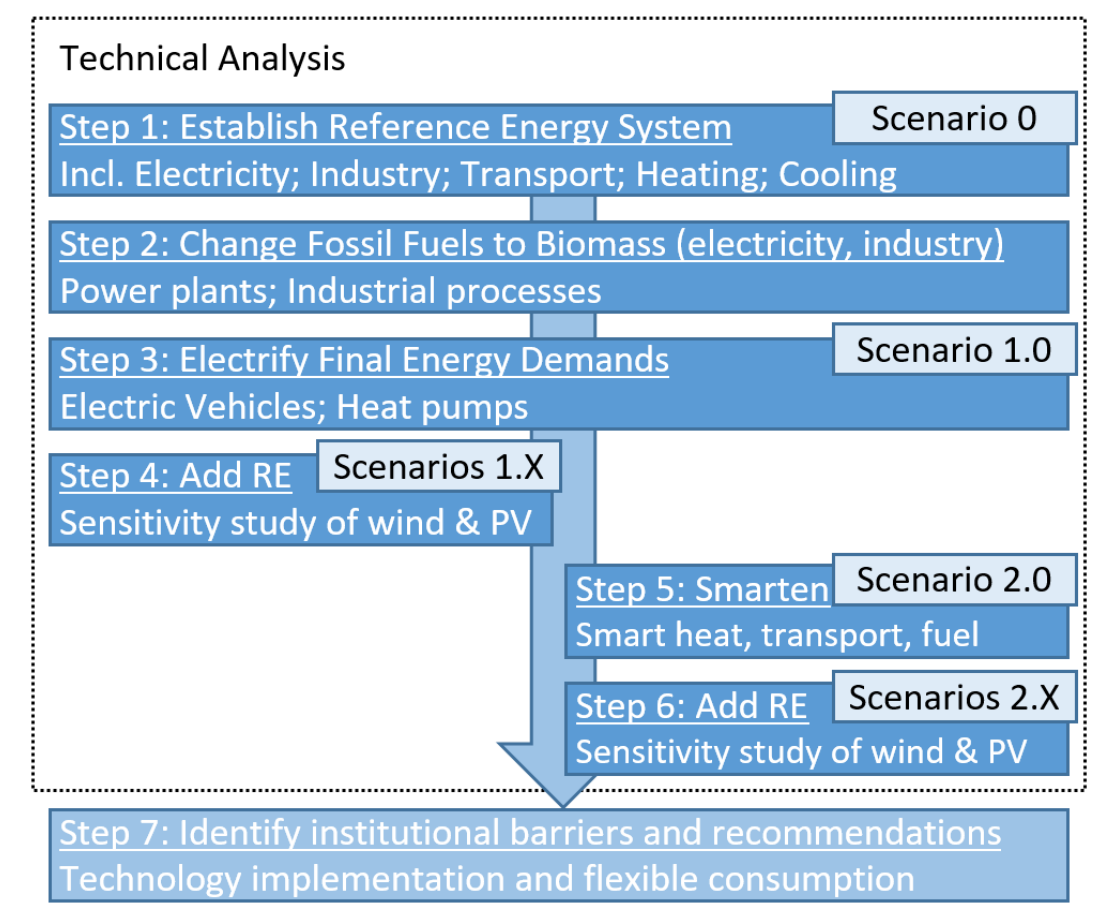

Figure 1. Step-by-step approach to scenario development and analyses.

\subsection{Scenario Approach}

While Section 1 presents the complexity of energy planning approaches, these are further complicated through geographical and economic boundaries. The selected choice of technical approaches would result in a variety of options and outcomes. Therefore, the following presents the introduction of the scenario development for the case study of Madeira Island, which is to test these approaches under its unique boundaries, for the reader to draw the consequences for other cases. Hence, this theory-led case study was used to test the theory that the smart approach is more beneficial than the electrification approach, and thus can be used as a valid argument based on this case [31]. The case can also be understood as an instrument to understand the suggested approaches through illustration in a certain context. Thereby, a quantitative approach was used to illustrate the explored issue of the case as well as a qualitative one where this event was portrayed.

In the following, the methodology for the creation of scenarios is shown. This approach is chosen to analyze the different impacts of the various steps that are introduced to the system. This way, alternative outcomes are created to show future development paths and corresponding implications [32]. Based on these scenarios, which present radical changes to the energy system, the market is evaluated. 


\subsubsection{Reference Energy System}

The case study to which the above mentioned was applied was the energy system of Madeira Island and its model was based on the SMILE project. With approximately 260,000 inhabitants and an annual electricity demand of $830 \mathrm{GWh}$, it is an energy intensive island but also a completely autonomous energy system with a large service sector, complex infrastructure as well as some industry. Without a significant heat or gas network, it presents a special but real case of an isolated island to learn from $[2,33]$.

The Madeira model was based on 2014 data (cf. Supplementary Materials) from local energy accounts and supported with data from local statistics and the electricity company of Madeira (EEM), so the production and consumption data was aligned and verified for all included sectors: electricity, heating, industry and transport [2]. In order to use this case study to evaluate the two approaches of $100 \%$ RE systems, this 2014 model was adapted to data from 2018 [34]. This resulted in the Reference Scenario 0 and concluded Step 1 of the methodology presented in Figure 1. With a high share of power supply from oil and gas based power stations, heavily oil-based transport and industry sectors, the energy system of Madeira Island was a good case study to evaluate the upcoming required transition to $100 \%$ RE in the two suggested approaches.

\subsubsection{Steps to a $100 \%$ RE System}

Based on Lund, the possibility of a $100 \%$ RE system is designed in three steps: energy savings, efficiency improvements and fossil fuel replacement with renewable sources [13]. The savings and efficiency were outside the scope of this paper, but the possibilities of replacing fossil fuels were evaluated within the technical analysis. This limitation confined the results to some extent but on the contrary shows what is technically possible only through the supply side. This was concluded in Step 2 by replacing the fossil fuels in the combustion processes of power stations and industry with biomass. The introduction of other RE sources in Steps 4 and 6 addresses the resulting high consumption of biomass.

Step 3 follows Step 2 with fossil fuel replacement in the transport and heating sectors. With Step 2 as an intermediate step away from fossil fuels, only Step 3 entails a scenario. Based on Lund, "oil for transportation is replaced by electricity" and "boilers are replaced by electric heating" [13]. After the introduction of electric vehicles (EVs) and heat pumps, respectively, this resulted in Scenario 1.0, which concluded the basic steps to $100 \%$ RE. This scenario was technically $100 \%$ renewable, yet potentially not sustainable, depending on the biomass availability and use. Step 4 is therefore the final necessary step to the $100 \%$ RE scenario of the electrification approach, where the RE was further explored through the expansion of PV and wind turbine capacity. This requires a sensitivity study to target scenarios where biomass is reduced by at least $50 \%$ while limiting critical excess electricity production (CEEP; often resulting in curtailment) to $100 \mathrm{GWh}$ and avoiding a large increase in total annual costs (max. 25\%). This resulted in Scenario(s) 1.X-with the " $X$ " standing for a potentially limited number of scenarios.

The second approach to a $100 \%$ RE system brings us to Step 5 and additional sector integration-or the smart energy system (SES) approach, which takes Step 3 to a new level by increasing the technological complexity. Aligned with the discussion in Lund et al. [35], alternatives were introduced to the electricity-focused improvements in the energy system from Step 4, namely smart charging and V2G, thermal solar collector and thermal energy storages (TES) in combination with the flexible heat pumps, and electrofuel production [35]. The latter is illustrated in the example of electrolyzers, hydrogen storage and shifting some transport demand to hydrogen vehicles. This introduced smart technologies beyond the simple electrification scope, by making further use of smart transport, heat and fuels. While the electrification Scenarios 1.X could benefit only from electricity storage, this integrated energy system allowed system-wide balancing through TES, hydrogen and car batteries, resulting in Scenario 2.0. Compared to the electrification approach, also Step 6 makes use of a sensitivity study to compare to Scenarios 1.X and identify potential benefits over the electrification approach, resulting 
in Scenarios 2.X. The changes that result in the 'smart 100\% RE system' were achieved through the modeling tool EnergyPLAN, explained in the following, traceable through the scenario data in the Supplementary Material.

Based on [32], the sensitivity study allowed for evaluating the impact of fluctuations of certain parameters on the outcome in a system, such as the energy system model. In the context of this study, the parameters were additional PV and wind capacity to minimize uncertainty of their contribution to the sustainability of the energy system. The capacities varied between 0 and $250 \mathrm{MW}$ in eleven steps of additional capacity each, presented in 3D surface diagrams of 121 possible combinations. Besides the scenario targets in biomass, CEEP and costs, the following key performance indicators (KPIs) were added to evaluate the results of the sensitivity studies and complete the sociotechnical analysis: RE share of primary energy supply (PES) and electricity supply, sustainable share (not including biomass-based electricity) of electricity, $\mathrm{CO}_{2}$ emissions, total and peak electricity demand.

\subsection{Modeling Tool EnergyPLAN}

The case study's energy system was modeled in its reference set-up, as well as through every step introduced above, with Aalborg University's EnergyPLAN v15.0 modeling tool [36]. Its ability to model all sectors, especially in relation to each other, as well as the hourly resolution makes it suitable for this research. The software allows for the characterization of the electricity, heating, transport and industry sectors as well as any fuel usage beyond these. Depending on the production, conversion and consuming units included in the manual setup of the energy systems, the sectors can be modeled separately or integrated, allowing for an evaluation of the steps and technologies accordingly. Hence, it allows for a comparable simulation of the two proposed approaches in its varying and-compared to the business as usual-increasing complexity. Related modeling material can be found in the Supplementary Material.

The KPIs can be retrieved in a collective way either for the whole energy system and the full year or by sectors and individual hours. They present the technical and socioeconomic perspectives of this research through the sociotechnical analysis, while also giving indication to the institutional ones. For the socioeconomic part, all costs are considered, including investment, fuel and operation costs as well as $\mathrm{CO}_{2}$ costs but no taxes. When comparing to the reference system cost, the KPI only presents the total annual cost. The option in EnergyPLAN to run serial calculations facilitates the elaboration of sensitivity analyses. By allowing the sensitivity parameters to fluctuate in up to eleven calculation steps and twelve output definitions, the KPI targets are supplemented in a comprehensive way. Finally, the technical optimization option in the tool allows for optimal balance of selected RE capacity according to available technologies, e.g., dynamic EV charging or flexible hydrogen demand depending on the defined storages. Hence, the smart additions to Scenario 2.X are made within EnergyPLAN by adjusting the model and operation accordingly for the points presented in Step 5.

EnergyPLAN has been applied in multiple studies of national $[37,38]$, regional $[39,40]$ and island energy system perspectives [20,21]. With various combination options of supply, conversion and storage technologies (cf. flow diagrams, [36]), the energy system model can be set up as required, which results in Figure 2. Mathiesen et al. [41] present the energy flow diagrams for various technical simulations, presenting similar steps in the transition to $100 \%$ RE. These can be modeled in EnergyPLAN and adapted to illustrate the current technical analyses and may further be related to the institutional analyses. In Figure 2, the energy flow diagrams represent Scenario 0 as a traditional energy system with no apparent cross-sector interaction, and the two following flow diagrams illustrate the two approaches of Scenarios 1.X and 2.X. The 1.X diagram shows the addition of RE and electrification of transport and heating and 2.X shows the addition of V2G, solar thermal, hydrogen production and various storage options. 


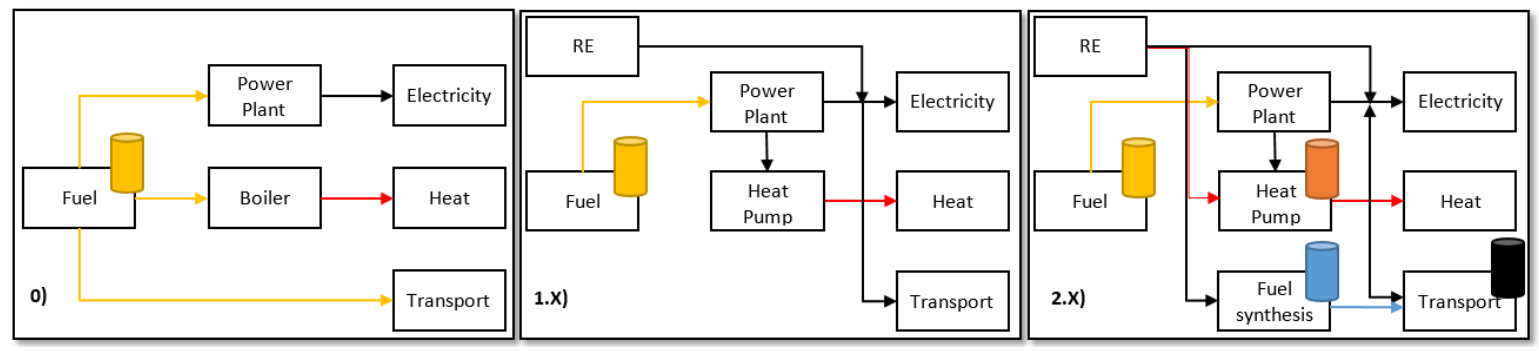

Figure 2. Energy flow diagrams for different energy system and market relation setups based on Scenarios 0, 1.X and 2.X, simplified, based on [36] (barrels indicating storage options).

In relation to the technical changes between the sectors and technologies, also the market setup changes accordingly (cf. Figure 2), indicating where requirements in the market are shifting and need to be supported. Where electricity, heat and transport were mostly regulated by individual markets before, the increased complexity and interrelations of technologies in Scenarios 1 and 2 need to be reflected in the future market setup as well. These institutional perspectives lead to the methodology for the market analysis in the following.

\subsection{Market Analysis Approach}

Based on the technical modeling, the two approaches to 100\% RE require strategical institutional support through the evaluation of the current and required future market structures. Hence, the market analysis represents Step 7, as it is based on the previous six steps but follows its own structure. The aim is to evaluate the current local barriers, potentials and requirements to support the technical scenarios with recommendations for potential changes in the energy market. As mentioned above, it is proposed to align technologies with social and market aspects [13], and to identify maximal preparedness for energy-related crises at all levels [28]. Even though islands are not specifically mentioned, they can present solutions in test scales for larger systems and markets through technical and institutional case studies.

Markets are usually defined as a variation over the theme "physical or virtual arena for the exchange of goods and services" and with particular reference to the energy sector, two types of markets are of relevance: markets for the exchange of technologies and markets for the exchange of energy or power. Thus, market analyses can address whether potential buyers in a given area have a ready access to, e.g., heat pumps or electric vehicles or vice versa whether heat pump and electric vehicle suppliers are met by willing buyers. Market analyses can also focus on how energy, e.g., electricity, biomass and electrofuels are traded with a view to ensuring a functional market that can help exploiting the flexibility options in the energy system with a view to integrating fluctuating RE sources. The main understanding applied in this paper is the latter-i.e., the trading schemes for power and/or energy, which improve the operation of the energy system. The trade of technologies is, however, a prerequisite to this and therefore touched upon as well. Furthermore, the market can be viewed from either the supplier or the consumer side, where the latter is evaluated in this paper by analyzing how the market should be designed from an end-user point of view.

Besides the system and market setup comparison in Figure 2, the following structural approach was used. Based on Hvelplund and Djørup [27], the analytical process can be divided into three phases, which relate to the sociotechnical analysis and lead to institutional considerations and alignment for this radical change. As presented above, changing the energy system's infrastructure to $100 \% \mathrm{RE}$ supply with either approach can be considered radical. The phases are based on each other and defined as follows:

- Phase 1 presents technical scenarios with certain goals, here $100 \%$ RE, including socioeconomic data;

- Phase 2 identifies the institutional context and shows the existing barriers and benefits for the scenarios; 
- Phase 3 leads to new recommendations or concrete design proposals; here applied to market structures.

The market analysis in Section 4 presents the phases as follows. After developing the scenarios in Section 2.1 (Phase 1), barriers can be identified and recommendations made. In detail, Phase 2 follows the scenario development and aims at analyzing its results in the current institutional context, e.g., if the scenarios are working in the current market, resulting in the identification of barriers and potentials. In order to do this, the context that shapes their implementation, such as current market and price structures, are taken into account. This is presented in Section 4.1. Phase 3 and Section 4.2 focus on resulting requirements for the future context by addressing the barriers from Phase 2 and supporting the technical scenarios from Phase 1, introducing recommendations that may not have been tested and/or have been blocked by institutions before; hence, new social dynamics might be the result [13]. For this, current and future regulations, considerations and proposals for short- and long-term changes in organizations and infrastructure can be named [27].

In this paper, the market analysis aimed for the 100\% RE goal presented in the technical analysis, which was analyzed and discussed, and what institutional barriers need to be addressed to support its implementation was investigated. Equal to Phase 1, both Phases 2 and 3 were studied in the context of Madeira Island and specifically in the context of end-users. This was done through a quantitative review of the technical scenarios, literature review and engagement with local stakeholders [33,42,43].

\section{Sociotechnical Analysis}

In this section, all steps and scenarios are presented, for which the results, including the KPIs, can be found in Section 3.3. The corresponding institutional market analysis follows in Section 4 .

As described in Section 2.1, the Madeira Island energy system model from 2014 formed the basis for the reference scenario and was updated in Step 1 of the analysis. This included the decommissioned hydropower station, as well as newly installed hydropower and PV capacities between 2014 and 2018 . Hence, $50 \mathrm{~kW}$ of additional PV and $30 \mathrm{MW}$ of dammed hydro power capacity with $16.5 \mathrm{MW}$ pump capacity were added, while an older hydro power plant of 3.5 MW was decommissioned (based on communication with EEM in January 2020). This resulted in the Reference Scenario 0 to which later scenarios were compared. This energy system had a RE share in PES of $11 \%$ and in electricity supply of $30 \%$.

\subsection{Electrified $100 \%$ RE System}

Corresponding to the scenario methodology in Section 2.1, the following Steps 2 and 3 replaced all fossil fuel with biomass or electricity. While switching to biomass in combustion processes did not entail any technical adaptions in the model and its operation, the transport and heating did. The change from petrol and diesel cars to EVs included a change of efficiency in addition to the different input. While oil-fuelled vehicles were estimated to drive $1.5 \mathrm{~km}$ per $\mathrm{kWh}$, EVs were assumed to drive $5.9 \mathrm{~km}$ for the same unit of energy input (EnergyPLAN assumption). In regard to heating, all boilers still using gas, biomass and oil had efficiencies of $<90 \%$, while heat pumps had an equivalent of $300 \%$ (COP of 3.0; considered constant based on average annual value), so the overall amount of required input was reduced drastically by the end of Step 3 .

With the change to biomass in power plants, the electricity sector reached a $100 \%$ renewable share, whilst the inclusion of the remaining sectors of industry, transport and heat also led to a $100 \%$ share in the PES (cf. Scenario 1.0, Table 1). The sustainable share of electricity, however, was the critical voice for when biomass was considered renewable yet not completely sustainable. As it is unknown if this amount of biomass is currently fully sustainable to harvest and combust, this was a caution factor. While the amount of biomass increased 16-fold, the $\mathrm{CO}_{2}$ (from fossil and waste combustion) reduced by $98 \%$ from the reference scenario. Electricity demands increased by $38 \%$ and $29 \%$ for total and peak demand, respectively. 
Table 1. Overview data of the main scenarios.

\begin{tabular}{cccccccccc}
\hline Analysis & Step $\mathbf{1}$ & Step $\mathbf{2}$ & Step $\mathbf{3}$ & Step $\mathbf{4}$ & Step $\mathbf{5}$ & Step $\mathbf{6}$ & Step $\mathbf{6}$ & Step 6 \\
\hline Scenario & 0 & - & 1.0 & 1.1 & 2.0 & 2.1 & 2.2 & 2.3 & \\
\hline Additional PV capacity & 0 & 0 & 0 & 100 & 0 & 250 & 50 & 250 & $(\mathrm{MW})$ \\
\hline Additional wind capacity & 0 & 0 & 0 & 200 & 0 & 75 & 225 & 225 & $(\mathrm{MW})$ \\
\hline RE share of PES & 11.0 & 56.1 & 100.0 & 100.0 & 100.0 & 100.0 & 100.0 & 100.0 & $(\%)$ \\
\hline RE share of electricity & 30.2 & 100.0 & 104.8 & 112.7 & 103.9 & 104.0 & 105.3 & 111.8 & $(\%)$ \\
\hline Sustainable share of electricity & 26.3 & 26.3 & 19.1 & 77.6 & 18.3 & 71.3 & 70.7 & 99.4 & $(\%)$ \\
\hline CO $_{2}$ emissions & 885.4 & 450.6 & 16.4 & 16.4 & 16.4 & 16.4 & 16.4 & 16.4 & $(\mathrm{kt})$ \\
\hline Biomass demand & 172.9 & 1885.3 & 2762.6 & 1370.2 & 2854.2 & 1360.9 & 1419.4 & 716.7 & $(\mathrm{GWh})$ \\
\hline Total electricity demand & 838.9 & 838.9 & 1156.8 & 1220.2 & 1203.1 & 1284.7 & 1285.9 & 1315.9 & $(\mathrm{GWh})$ \\
\hline Peak electricity demand & 140.0 & 140.0 & 180.8 & 205.6 & 218.0 & 358.8 & 337.6 & 491.0 & $(\mathrm{MW})$ \\
\hline Total annual costs & 319.3 & 279.4 & 396.3 & 392.9 & 404.2 & 396.3 & 398.0 & 397.6 & $(\mathrm{~B})$ \\
\hline CEEP & 0 & 0 & 0 & 92.1 & 0 & 0 & 17.0 & 95.5 & $(\mathrm{GWh})$ \\
\hline
\end{tabular}

The next Step 4 is illustrated in Figure 3, where the electrified energy system was analyzed in a sensitivity study with various additional RE capacities. The results were reconciled with the target criteria, where biomass was reduced by at least $50 \%$ and CEEP was kept to $<100 \mathrm{GWh}$, which resulted in only one option: Scenario 1.1.

Biomass demand

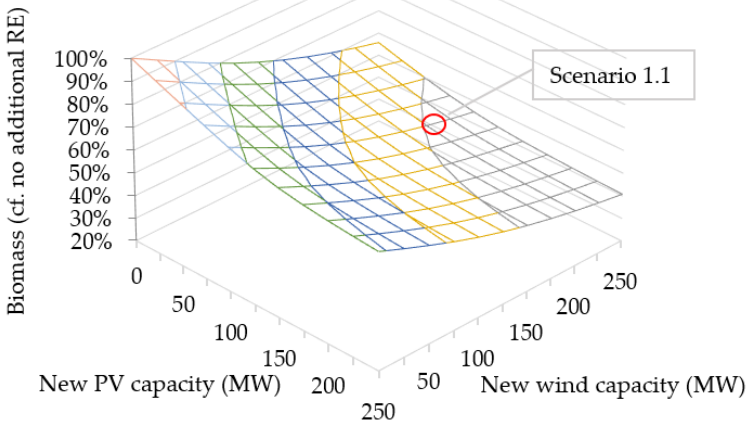

CEEP

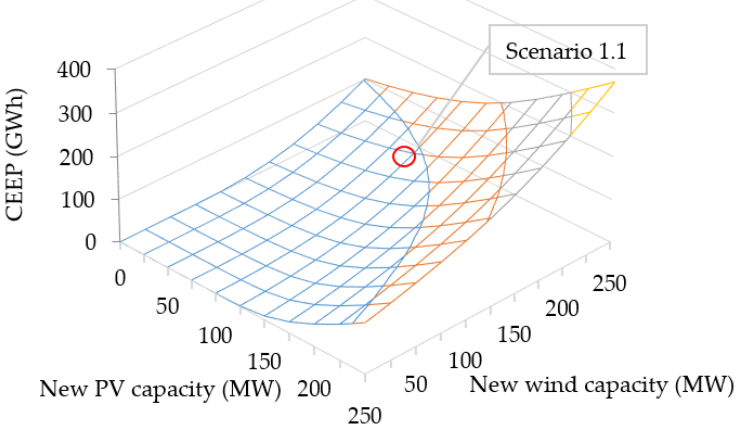

Figure 3. Sensitivity study for an electrified energy system, including optimal Scenario 1.1—resulting additional biomass demand and critical excess electricity production (CEEP).

By addressing these criteria, Step 4 resulted in the additional capacity of 100 MW PV and 200 MW wind but also increased the sustainable share of electricity to $77.6 \%$. Hence, in technical terms, the energy system of Madeira Island was now 100\% renewable and supplied by $60 \%$ RE through wind, $\mathrm{PV}$, and the other previously installed RE, while the remaining $40 \%$ was supplied by biomass combustion. As can be further noted from Figure 3, the biomass consumption reduction stagnated shortly after the $50 \%$ reduction target (even with $250 \mathrm{MW}$ PV and wind each, it reached $59 \%$ biomass reduction). Furthermore, only 9 out of the 121 possible scenarios resulted in 0 CEEP, but here the biomass reduction potential was below $20 \%$. The details of Steps 1-4 and the Scenarios 1.X can be found in Table 1 next to the results from Steps 5 and 6 and its corresponding scenarios 2.X, which are explained in the following.

\subsection{Smart $100 \%$ RE System}

Firstly, the smarter heat entails an intensification of thermal solar collectors-double the capacity, as well as TES - to supply $100 \%$ of households and for a maximum period of 10 days, which optimizes the operation of the heat pumps. Secondly, the smartening of the transport demand including V2G requires the addition of the right grid-to-battery capacity and vice versa. The maximum share of cars 
charged during peak and the share of grid-connected cars was defined as 50\%, and total battery storage capacity was $5 \mathrm{GWh}$. Thirdly, the smart fuel addition entailed the introduction of electrofuel through the example of an electrolyzer to produce hydrogen and $20 \%$ of the transport demand to be covered with it, as well as the option of hydrogen storage of $100 \mathrm{MWh}$. All three steps increased the electricity demand but reduced the CEEP. In EnergyPLAN, the electricity demands of EVs and the electrolyzer were flexibly modeled according to the RE production.

Step 5 resulted in Scenario 2.0, which is similar to Scenario 1.0 but slightly more expensive due to its complexity. The following sensitivity study in Step 6 therefore was required to show its full potential. Step 6 addresses the same target points as Step 4 to increase sustainability shares through reduced biomass amounts, costs and CEEP. In contrast to Step 4, where only one scenario fulfills the targets, the SES approach offered 41 possible options within the same criteria. The following proposed scenarios therefore could further address potential limitations in available land and visual impacts if required. Scenarios 2.1 and 2.2 thus demonstrated mainly PV or wind, respectively, while Scenario 2.3 did not consider any of these limitations. The results of this sensitivity study can be found in Figure 4, which shows that biomass reduction potential spanned longer than in the electrification scenario (1.X) with up to $77 \%$ biomass reduction at full additional capacities of $250 \mathrm{MW}$ each. Furthermore, CEEP can be avoided in 72 out of 121 possible combinations and remained below $100 \mathrm{GWh}$ in all but three options.
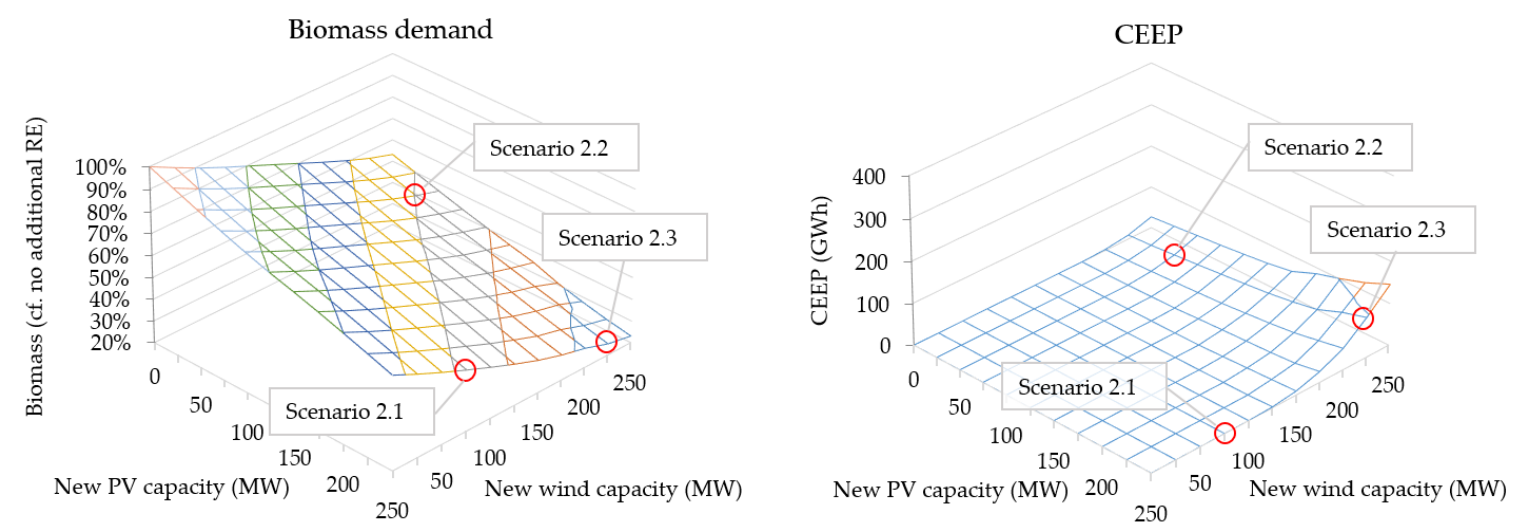

Figure 4. Sensitivity study for a smart energy system, including proposed scenarios—resulting in additional biomass demand and CEEP.

The three proposals out of the 41 options of PV-wind combinations can be pointed out in Figure 4. All proposals show a different extreme in terms of RE capacity, as well as consider potential limitations, so either one could be recommended to the island of Madeira depending on local requirements and wishes.

The first SES scenario included the maximum PV capacity within the sensitivity study and required a minimum wind capacity of $75 \mathrm{MW}$ to reach the biomass reduction of $>50 \%$, which was not possible with $50 \mathrm{MW}$ wind capacity (48\%). It is one out of five scenarios that fulfilled the criterion and remained at 0 GWh CEEP, which was not possible with the electrified energy system scenarios. With the increasing opposition to wind turbines and potential available space on rooftops, among other challenges, this "PV Scenario 2.1" may be the preferred option to the local community. Despite only minor differences in the total annual costs, this scenario also presents the cheapest solution under the smart system approach.

The second SES scenario presents a wind-favored option, at almost maximum wind capacity and minimum PV capacity within the target criteria range. With $225 \mathrm{MW}$ additional wind and $50 \mathrm{MW}$ PV capacity, the CEEP was kept at 17 GWh annually, which corresponded to $2 \%$ of the electricity production. As can be seen in Table 1, the peak demand was the lowest in this scenario; however, this resulted from the peak supply delivered by the wind turbines and the smart charging and hydrogen 
production accordingly. This overall lowest total capacity further entailed the overall lowest number of new installations, since capacities of single wind turbines was much higher than PV systems, therefore this more centralized concentration of RE could be preferred.

The third proposed scenario, Scenario 2.3, aimed at the highest biomass reduction while staying within the CEEP limitations, and even within the cost requirements, as it is even cheaper than Scenario 2.2. With the CEEP value of $95.5 \mathrm{GWh}$, which represents $6 \%$ of the production, a biomass reduction of $75 \%$ could be achieved, resulting in a $9 \%$ share of biomass for the electricity supply. For this, $250 \mathrm{MW}$ PV and $225 \mathrm{MW}$ wind capacity was installed, which, however, ignores the potential space and visual limitations that might exist. It presents, however, an option if biomass is to be limited. This way, Scenario 2.3 was the most sustainable scenario with a sustainability share of $99 \%$. For all scenarios with large PV and/or wind capacity, environmental aspects in their production could be considered.

Alternatively, if none of the above presented scenarios appears optimal after all, a compromise or combination of their aspects could be considered. For example, if suitable land for wind turbines are limited but should still be included, other scenarios could be further evaluated with Figures 4 and 5 . Regarding biomass reduction, 15 combinations require $<1000 \mathrm{GWh}$ biomass; and regarding CEEP increase, 72 combinations are at $<0.1$ GWh CEEP and another 27 within $0.1-25$ GWh CEEP. Finally, the target criteria of cost limitation are presented in Figure 5, where the socioeconomic cost development of the scenario is illustrated in comparison to Scenario 1.1. In contrast to the biomass consumption and CEEP, it did not develop linearly but shows the optimal scenarios at PV capacities above $175 \mathrm{MW}$ and wind capacities between 50 and $175 \mathrm{MW}$. Regarding annual socioeconomic costs, Scenario 2.1 would be the most secure in this regard, but further 11 other combinations would be as well.

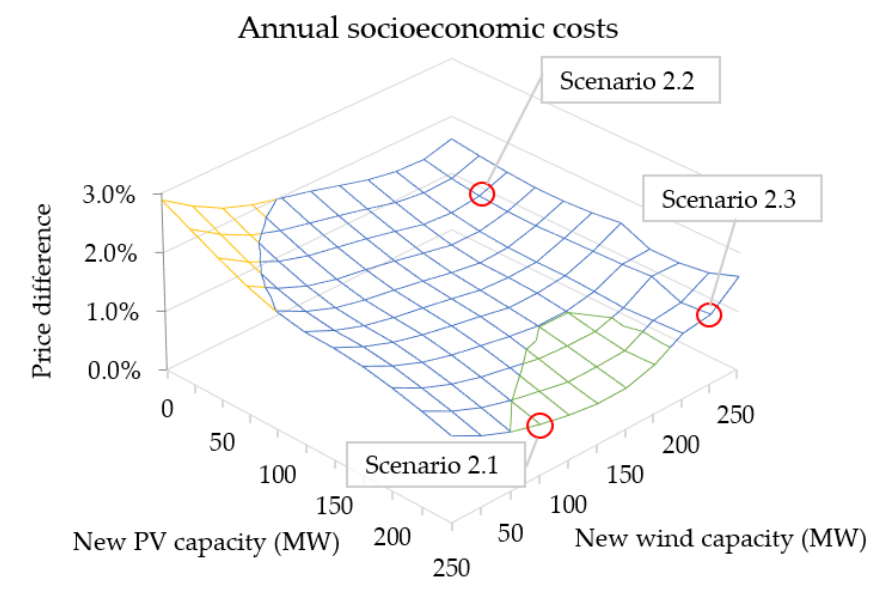

Figure 5. Sensitivity study for a smart energy system, including proposed scenarios-resulting annual socioeconomic costs, relative difference to Scenario 1.1 .

\subsection{Comparison}

When comparing the technical analyses of transitioning to $100 \%$ RE on Madeira Island, the SES approach presented more options and thereby more benefits than the simplified electrification approach, addressing all KPIs. This was clarified with an overview in Table 1 and illustrated in Figure 6. Both alternatives achieved $\mathrm{CO}_{2}$ reductions and higher shares of renewable and sustainable sources. Compared to the reference case, Scenario 1.1 reduced the $\mathrm{CO}_{2}$ emission by $98 \%$ but increased the biomass consumption by $690 \%$, the annual and peak electricity by $45 \%$ and $47 \%$, respectively, and the annual costs by $23 \%$. Scenarios 2.X achieved the same $\mathrm{CO}_{2}$ reductions and similar changes compared to the reference. The remaining $\mathrm{CO}_{2}$ emissions were related to the waste incineration. 


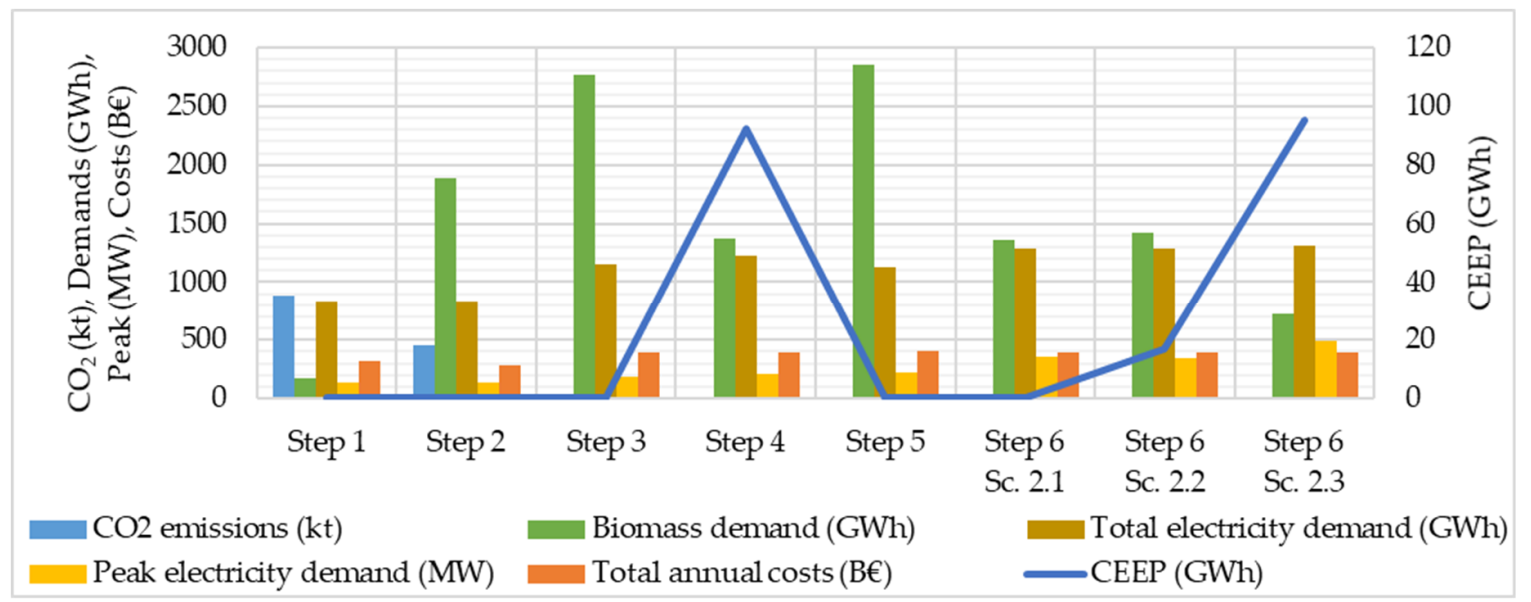

Figure 6. Overview of selected key performance indicators (KPIs) of the main scenarios.

When comparing 2.X with 1.1, however, biomass could be reduced by up to $52 \%$, CEEP by $100 \%$ while costs increased by $0.7-2.9 \%$. Overall, the 2.X scenarios show more possibilities for potential local restrictions. While Scenario 1.1 could achieve the biomass, CEEP ( $7 \%$ of total electricity production) and cost targets only in one PV-wind combination, the Scenarios 2.X present 41 combinations. If one specific target was in focus, e.g., CEEP limitations, the sensitivity study of Scenarios 2.X presents 72 combinations where CEEP can be avoided completely. This concerns only 9 out of the total 121 options for the $1 . X$-scenarios.

While $100 \%$ RE share of PES was reached after Step 2, the sustainable share, where biomass was used as little as possible, reached $70-99 \%$. When taking into account the sustainability available biomass on Madeira Island, this could be elaborated. The share of RE of electricity reached values above $100 \%$ if the production exceeded the demand.

Complementary to Table 1, Figure 6 illustrates selected KPIs. While $\mathrm{CO}_{2}$ emissions dropped drastically within the first two steps, biomass consumption increased until RE was added. Still, electricity demands were increasing with each step, similarly to the costs. While electricity demands increased by $57-350 \%$, the costs increased by only $24.5 \%$ compared to Step 1 . When including the additional CEEP values, the dependency between all KPIs is shown.

The basic electric approach is nonetheless an essential part of the transition to $100 \%$ RE share, while the additional smartening of the energy system can be understood as a potential, yet beneficial, second step. According to this, the market analysis addresses both approaches in the following section as a supplement and preliminary discussion for the implementation of proposed technical scenarios.

\section{Market Analysis}

Based on the above sociotechnical analysis of the two approaches to $100 \%$ RE share on Madeira Island, the institutional barriers and market requirements are addressed in the following. It becomes clear that the SES approach has more benefits in technical and sustainable terms and allows for several combinations of wind and PV capacities while being in line with the scenario targets. However, Scenario 1.1 competes with Scenarios 2.X in socioeconomic aspects and is otherwise an essential baseline for the potential uptake of smartening afterwards. The following institutional analysis therefore contributes to the comparison of the two approaches and sees Scenario 1.X as a basic first step and Scenarios 2.X as a necessary second step in the market for an optimal transition to 100\% RE.

The main barriers that are not apparent in the technical scenarios in EnergyPLAN, however fundamental, are the implementation of the modeled scenarios with their corresponding technical requirements. Specifically, the island-wide change to electric heating and transport can be connected to radical changes in people's homes, public buildings and infrastructure. Additionally, the SES approach includes flexibility options that require the production of hydrogen, heat from heat pumps and the 
V2G in accordance to the RE power production. While this is modeled optimally in EnergyPLAN, incentives, regulations and/or market redesign are required for implementation.

The following therefore addresses this issue on the consumer side as the key technologies can be found there and also to increase consumer participation in the energy planning. As introduced in Section 1, the European Commission proposes an integrated energy market, where the consumers are put at the centre of this transition. As this paper focuses on the opportunities of EVs and heat pumps, Section 3 shows how the consumer is required to help in this part of the transition. This may be an important aspect in order to address the implementation and flexibility issue, if planned accordingly in this institutional setup. Furthermore, the encouragement and engagement of the consumers allows not only for wider acceptance of required technologies but also results in benefits for the grid operator if their interests align through increased grid flexibility.

\subsection{Barriers}

As explained in Section 2.2, the technical analysis influenced the institutional one as the complexity in the technologies was also reflected in the market complexity. With more technologies on the supply, conversion and demand sides, as well as in balancing in the SES approach and improving cross-sector integration, the supporting institutional framework also needs to be addressed. Here, the decentralization in the energy sector requires a different focus to involve consumers more.

In the past-in contrary to the two proposed approaches-energy systems were dealt with separately and markets were centralized and based on fossil infrastructure, hence balancing, integration or alignment was not as complex. With the increase of fluctuating RE, this stability is affected, requiring technical and economic adjustments, as energy production and market complexity increases. When aiming at $100 \%$ RE systems, hence, the institutions and markets as we know them need to move away from the paradigm of fossil fuel being at the centre of the energy market. By coordinating the integrated market prospected by the EU, the consumers are put at the centre of the energy market and smart technologies would be allowed to become competitive.

The introduction of the smart energy markets concept [24] shows the direction these RE-based systems can have, although they must be adjusted to the limitations of islands and be more focused on the self-sufficiency of energy systems with limited resources. As transmission lines might not be available and imports can be uneconomical, the local integration through electrification of additional SES aspects is important. However, the markets of islands are usually set up in a similar manner as the national market, which does not have the same limitations. This leads to the increased necessity on islands of, on the one hand, decentralized and local utilization of RE for electricity, heating and transport demands and, on the other hand, flexible demand and balancing. Both the electrification as well as the SES approach can be evaluated accordingly.

In Madeira Island, the incentives to increase both the local utilization and the flexible demand are limited. While incentives exist for the purchase of EVs at national [44] and regional [45] levels, the number of EVs is still limited, showing that the incentive might not attract enough people. Barros et al. [42] further show that the average EV user on the island has an income above average, and that the general conception of EVs is still hesitant-either regarding battery lifetime, charging time or suitability for the island orography. Despite the current option of free public charging for EVs, their share on the island is less than $1 \%$.

Incentives for purchasing heat pumps, TES or even electrolyzers and hydrogen vehicles are not available at all as of writing. If the consumers are to increase their use of these technologies, it is necessary to make them understand their benefits, addressing the hesitance and criticism by working on the acceptance and understanding from the end-user perspective. While this is a barrier, it can also be a potential to explore through the local consumer-involved energy market.

On the other hand, incentives for flexible consumption are in theory available for all sectors, yet with a limited reach so far. The local transmission system operator (TSO)/distribution system operator (DSO; EEM) together with the national energy services regulation entity (ERSE) introduced 
time-of-use tariffs to address the local issue of high electricity demand peaks during the hours 9:00-13:00 and 18:00-22:00. The result was an optional choice between three main tariffs, which only change according to season (summer and winter season) and potentially weekdays (Monday-Friday, Saturday and Sunday), see Figure 7. According to EEM, the idea is to incentivize consumers to use electricity during the night, as this is when curtailment—or in the technical analysis CEEP—most likely occurs [43].

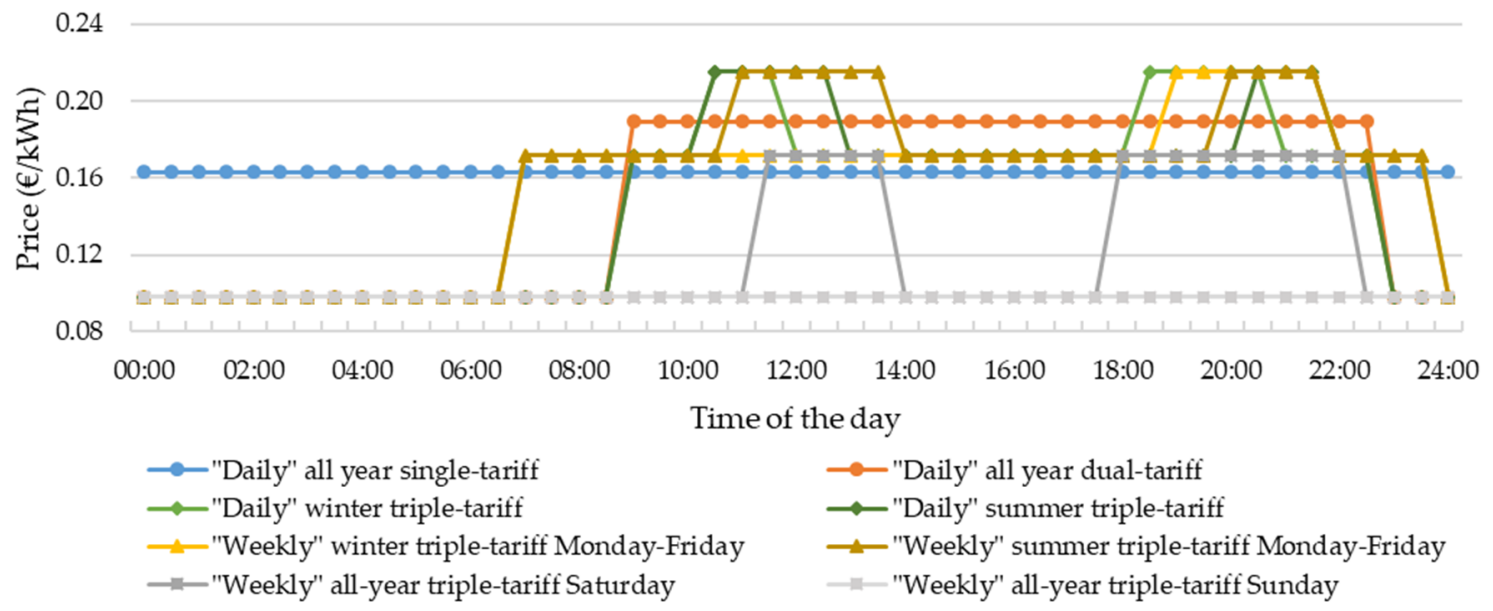

Figure 7. Time-of-use tariff options in Madeira, based on [43] ("Daily" indicating no difference between weekdays and "Weekly" indicating a difference between Monday-Friday, Saturday and Sunday).

Despite the free charging options, EV owners preferred to charge at home, either due to comfort or time constrains, but often excluding the tariffs in the considerations evaluated in [42]. On the contrary, Hashmi et al. [43] suggest that the daily tariffs are preferred without the cheaper weekend prices. While this limits the peak shaving, the local peak power contract (PPC) also has a restricting impact on the flexibility of consumption. The PPC is the maximum demand that consumers can draw from the grid and results in local power shutdowns if exceeded. Furthermore, single and dual tariffs are still the preferred option, not evidencing the benefit of EV charging at times when the electricity prices are cheaper and despite being better for the DSO/TSO.

Although incentives for more dynamic consumption are available, the current tariffs do not consider the actual sustainable share in the electricity mix. This price flexibility, yet inflexibility, has the same impact on encouraging the use of sustainable electricity in all sectors, as it does not seem to make a difference in price where the electricity is coming from. Hence, there is no difference if it is coming from a combustion plant-even though it might use biomass, it might not be sustainable due to the limited resource-or from the unlimited and sustainable sources wind or sun. Even though hydrogen is not yet much developed in Madeira Island, it plays an important role in illustrating the need for flexible production of an alternative fuel. However, examples from other islands show that there is currently no incentive to run the electrolyzer during windy/sunny times instead of during times of imported/combustion-based power, leading to the difficulty of producing green hydrogen, as is the case in the Orkney archipelago [46]. Overall, the use of best technologies at optimal times requires new approaches, which is addressed in the following.

\subsection{Recommendations}

The radical changes proposed and the barriers identified in the previous sections form Phase 1 and Phase 2 of the institutional analysis. In the following Phase 3, concrete changes to the market structure are suggested accordingly with a focus on end-users and energy markets though including basic aspects of the technology markets, as strategic energy planning suggests. 
As evidenced above, the consumer can be economically incentivized to use electricity at certain hours-in either the electrified scenario through heat pumps and EV charging or in the smart energy scenario through additional technologies. This can be done when it is also beneficial for the grid operator, resulting in a flexible and dynamic energy market, where the fluctuating RE production is in the centre. To allow for a dynamic market, the first step is the uptake of suitable technologies on the demand side. The number of EVs, heat pumps and potential electrofuel technologies require incentives that convince consumers to invest. This can be achieved by increased support and/or clarification of the long-term benefits and by considering all income groups, addressing the social barriers mentioned. The recently introduced incentives on both the local and national level present such benefits and should be secured and potentially elaborated in the future. This represents a prerequisite to implementing the smart scenarios and goes hand in hand with suitable financial incentives for electricity consumption, aiming at the second step to market dynamics. In line with this, [47] shows the importance of incentives at the right stage as they were evaluated to be better placed at operation than at purchasing state of EVs.

Semi-flexible electricity prices have been introduced to regulate the demand and encourage consumption outside peak hours through optional tariffs, but this is not yet widely done and must be adapted to a $100 \%$ RE system and to the sensitive energy systems of islands. However, the currently used time-of-use tariffs are not suitable for high RE scenarios and more flexible tariffs are suggested to overcome the existing barriers by including equality and transparency for the consumers [48]. In comparison with Figure 7, Figure 8 indicates a potential price mechanism according to RE production, with the option to take the electricity demand (projection) into account. Similar average daily prices of $0.15 € / \mathrm{kWh}$ are compared to the current tariffs, but with more extreme peaks, incentivizing dynamic consumption. This is shown in an example for 7th January, where consumption is encouraged during the windy night (and low demand), instead of the early evening, where ceasing PV and wind production (and high demand) increase the price between 15:00 and 20:00 drastically (cf. triple-tariff).

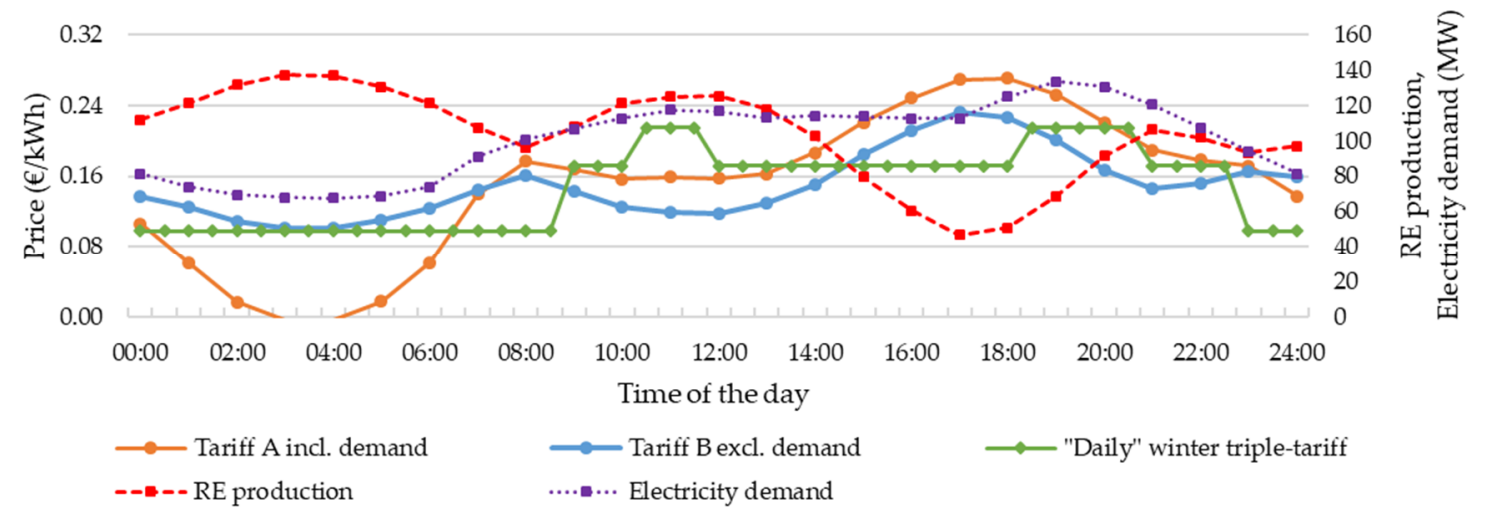

Figure 8. Proposed example of dynamic price mechanism resulting from renewable energy (RE) production including (tariff A) or excluding electricity demand (tariff B) on Madeira modeled in EnergyPLAN for 7 January.

This recommendation would make smart technologies competitive to the current use of fossil fuels. By taking into account the sustainability of the local RE production, the transmission and their costs, the price signals must be adjusted accordingly. With yet a small number of EVs but already a demand for peak shifting now, the need for scheduling is already pointed out, which will increase with additional technologies in the energy system and which will be possible with elaborating on the dynamic price mechanism proposal.

Hence, the current tariffs for end-users on Madeira Island (cf. Figure 7) can be the starting point but are recommended to become mandatory and more dynamic according to the sustainable electricity from wind and PV. Furthermore, the proximity of the consumer to the production side is 
to be taken into account to reflect the true transmission/distribution cost. As demonstrated in [49], proximity is a positive contribution to consumer behavior, and in [50], resulting lower prices for local consumers are argued to increase acceptance. Hence, the local TSO/DSO is to control and schedule price signals according to the technical capabilities of the overall energy system-similar to what is already done-but including further market perspectives by considering the consumer as a controllable load that requires incentives. This can be applied to EVs, heat pumps and other demands that allow flexible operation either through smart charging, TES or hydrogen storage capacity resulting from the first step. A smartly controlled or scheduled approach would also address the PPC problem and weather forecasts could also be considered in this recommendation. With increased digitalization, this and more can become an important attribute to future energy markets [51,52].

Similarly, the Madeira-specific free EV charging will not be possible for long. However, a low price for charging EVs can be negotiable according to the conditions by limiting it to hours of high sustainable energy shares. As [42] shows, some EV owners act according to price incentives when charging and they are suitable flexible consumers. This entails an expansion of charging options, not only public ones but also in business areas and smart charging support. While some solutions can be managed centrally, others may only be possible at private facilities, hence different tariff options can be considered respectively. When this is in place, a smart approach to V2G must follow to bring the full potential to the energy system by providing balance through short-term storage. This requires another economic incentive for the consumers at the household level, as their EV batteries' life cycle would be affected and the time to charge the EV battery prolonged. This is addressing the barriers of hesitance mentioned in Section 4.1 and is supported in [53], where remuneration is further elaborated. Thus, a selling price higher than the buying price is recommended, signaling the value to the market. If EV owners were not to be allowed to make a profit, this balance option would be limited to the DSO/TSO, showing an example of the importance of consumer involvement.

Though outside the scope of this paper, the limited uptake of RE capacity at the household level, where consumers become prosumers, would be further addressed with these recommendations. While there is now an injection limit from microproducers, such as PV owners, to the grid, the additional control of consumption through location-based prices could enable an easing of injection limits. This could further lead to household PV capacity increase, which may be required besides large-scale PV parks for the energy system in this paper, especially Scenario 2.1.

An overview of the two approaches, their barriers and potentials as well as recommendations can be seen in Table 2. As visible, the number of potentials is higher for the multi-energy SES approach, yet the market requirements address both approaches as the electrification still forms a first step towards the smart approach. Further discussion and recommended research can be found in the following section.

Table 2. Overview of the phases of the institutional analysis in relation to the technical analysis.

\begin{tabular}{|c|c|c|c|}
\hline Phase & Approach & Electrification (Scenario 1.1) & Smart energy system (Scenarios 2.X) \\
\hline 1 & Technical requirements & - RE power supply, heat pumps, EVs & $\begin{array}{l}\text { - RE power supply, heat pumps, solar thermal, TES, EVs, smart } \\
\text { charging, V2G, electrolyzer, hydrogen storage }\end{array}$ \\
\hline \multirow{2}{*}{2} & Barriers & $\begin{array}{l}\text { - High biomass consumption and/or } \\
\text { CEEP, few PV-wind combinations } \\
\text { - } \quad \text { Limited incentives for technologies } \\
\text { - } \quad \text { Limited incentive for flexible demand } \\
\text { Limits for consumer and grid operator }\end{array}$ & $\begin{array}{l}\text { - } \quad \text { Limited incentives for technologies } \\
\text { - } \quad \text { Limplex technological setup } \\
\text { - } \quad \text { inited incentive for flexible demand }\end{array}$ \\
\hline & Potentials & $\begin{array}{l}\text { - } \quad \text { Fewer technologies required } \\
\text { - } \quad \text { Flexibility to certain extent }\end{array}$ & $\begin{array}{l}\text { - } \quad \text { Less biomass consumption and CEEP, many PV-wind combinations } \\
\text { - } \quad \text { Flexibility through additional storage } \\
\text { - } \quad \text { High consumer involvement }\end{array}$ \\
\hline 3 & Market recommendations & \multicolumn{2}{|c|}{$\begin{array}{l}\text { - Support of RE-based technologies and consumption } \\
\text { - } \quad \text { Dynamic end-user tariffs, according to production and location } \\
\text { - } \quad \text { Control and scheduling of tariffs by local entities } \\
\text { - V2G incentive }\end{array}$} \\
\hline
\end{tabular}




\section{Discussion}

This paper fills the previously identified research gap by showing the needs and possibilities of Madeira Island to reach a 100\% RE share from both technical and institutional perspectives. To this end, two approaches are developed and compared to each other to show their strengths and weaknesses, and how they can be supported in the right way.

The importance of sector integration in a multi-energy system is presented in either approach as electricity demands can be found in the heating and transport sectors already and shows to be the way forward for the most dynamic and smart energy system as well, especially for islands. The paper shows how smart technologies and the inclusion of other energy carriers than electricity can be beneficial by providing flexibility. By using EnergyPLAN, the technical model simulates the optimal balance between the sectors and technologies. While technical analyses often do not consider the required institutional support, by adding a market analysis, the implementation potential of the technical scenarios is addressed in this work as a supplementary requirement for a full transition to high RE shares. Through consideration of the transition as being radical and analyzing market barriers accordingly, the importance of consumer involvement and demand response becomes evident. Therefore, the introduction of social parameters and local energy markets also proves to be important in islands and the presented transition.

With a three-phase institutional approach after the technical step-by-step modeling, the consumers are recommended to be more involved in the market, enabling benefits for both supply and demand sides. This entails the recommendation of institutional support, as the potential of flexible demand response can effectively be realized with dynamic pricing. This supports the implementation of the optimally modeled technical scenarios. With Madeira being a special case since its own local authority is in a position to develop this, it also shows how local power and regulation can be the key to local energy systems transitioning to $100 \%$ RE. On the contrary, if local entities are excluded, it can become a bottleneck for local energy market development.

The simplified electrification approach competes with the smart approach in socioeconomic terms by being $0.7-1.6 \%$ cheaper but at higher biomass consumption and/or CEEP. Hence, the smart technologies might be more costly, yet only marginally, while allowing for less biomass and/or CEEP. The overall increased annual costs (30\% more than the reference scenario) can be attributed to large investments, such as EVs, but should also be considered in the long term, when imports are reduced and the local economy benefits from it. The benefits in reduced biomass and CEEP may require investment and exploration of electrofuels, additional storages and technologies, yet it competes with the mere electrification with various RE options and limiting its capacity. The resulting optimized utilization of fluctuating RE production allows for higher peaks, yet better acceptability, flexibility and control, both from technical and consumer perspectives.

However, for the discussion and elaboration of analysis and results, further considerations and research is recommended, for example, a discourse on the technologies to implement and the biomass resource locally available. Outside this paper's scope and not further addressed, the underlying capacity required for the scenarios entail investment, installation and maintenance. While this is reflected in the total annual cost, the implementation can be further studied. Similarly, the knowledge and resources might be locally limited, influencing the proposed scenarios. Hence, if biomass is not suitable or limited for the power production supplementing the fluctuating production from wind, $\mathrm{PV}$ and hydro plants, a different combination of technologies or resources is required. As hydrogen is used as an example of flexible demand with various purposes, other electrofuels or synthetic products could also be considered. Furthermore, the sustainability of biomass can be elaborated as well as its transport across the islands versus decentralized exploration close to its origin.

The technical modeling is done on an hourly basis and thereby includes seasonal and daily variations. It could, however, be improved by using an intra-hour analysis, which might be especially relevant for a sensitive island system. Additional detailed market analysis could further advance this aspect of the paper. The proposed incentives for investments in EVs or heat pumps require 
further examination if every consumer would require them, but some limitations might be in order. With different options for smartening the EV sector, further study is recommended of both centrally operated and private options, such as the implementation of $\mathrm{V} 2 \mathrm{G}$ in order to increase the involvement of electricity consumers in the Madeira microgrid market. The final implementation of the tariffs would entail additional research of details not only for the electricity end-users tariffs but also for the integration of V2G. EV batteries degradation from excess of charging/discharging cycles has to be taken into account, as well as minimum EV battery range for users' daily commutes and EV users' disposal to have their vehicle available for the grid operations, specifically in hours with more RE.

Global market developments are to be taken into consideration, since the socioeconomic part of the analysis gives an impression but could be improved if prices for EVs or other investments drop. This also points out that the resulting total annual costs are very compatible with the reference since high investment costs are also included. Despite focusing on the consumers' side in this transition, energy efficiency measures are not included but could benefit it in various ways and be considered more in future research. Lastly, additional energy infrastructure, such as gas or district heating/cooling, could put further significance on a holistic energy market, making use of the various opportunities presented; and a study of other islands' consequential policies would be the final step. Overall, the complexity of energy system planning for low-carbon energy transitions and high RE shares is evident and the need for alignment of technical and institutional analyses presented through the perspective of islands but for the benefits of all.

\section{Conclusions}

The research gap is addressed by combining not only two different energy system planning approaches but also technical and institutional aspects of transitioning the energy system for the case of Madeira Island. The step-by-step approach to a 100\% RE and highly sustainable system is modeled with EnergyPLAN and addresses market barriers and potentials in the complementary institutional analysis. The impacts of the different steps in the transition are shown and the benefits of a smart energy system pointed out. The particular settings on the island are thereby included and the limitations and sensitivity of the energy system properly addressed.

It is shown that island energy systems require a more complex energy system and smart technologies to cope with the lack of cross-border trading, where local conditions are considered and self-sufficiency improved. Without the smart energy system approach, biomass consumption and curtailment are to be expected. This, however, requires support mechanisms that take into account the fluctuations and local restrictions of RE, where the role of the consumer becomes more important. In the case of Madeira Island with its own government, better local adaption can be expected as specific tariffs and incentives already exist specifically supporting the local situation.

The general need for better alignment with market aspects is pointed out for the implementation of the technical scenarios through recommendations resulting from a market analysis. It is illustrated how important the consumer is for capacity investment and flexible demand, which can only be reached with incentives for both installation as well as use of smart technologies. Specifically, dynamic electricity prices are recommended that align with the sustainable share of electricity and the local possibilities and restrictions.

The presented research can be replicated in other energy systems and become most relevant for those with sensitive or limited infrastructure but can also be relevant for those systems that aim for higher self-sufficiency and more independence even when being well-connected. With a well-planned transition to $100 \% \mathrm{RE}$, as is demonstrated with this paper, the replacement of fossil fuels and the fight against climate change can be achieved.

Supplementary Materials: The following are available online at http://www.mdpi.com/1996-1073/13/17/4434/s1, EnergyPLAN data and results. 
Author Contributions: Conceptualization, methodology, formal analysis, software, writing—original draft preparation, visualization, and project administration, H.M.M.; validation, investigation, resources, data curation, and writing-review and editing, H.M.M. and L.B. All authors have read and agreed to the published version of the manuscript.

Funding: This research received funding from the EU H2020 under Grant Agreement 731249.

Acknowledgments: Guidance and support from our supervisors are gratefully acknowledged.

Conflicts of Interest: The authors declare no conflict of interest.

\section{Abbreviations}

$\begin{array}{ll}\text { B€ } & \text { Billion Euros } \\ \text { CEEP } & \text { Critical excess electricity production } \\ \mathrm{CO}_{2} & \text { Carbon dioxide } \\ \text { COP } & \text { Coefficient of performance } \\ \text { DSO } & \text { Distribution system operator } \\ \text { EEM } & \text { Madeira electrical company } \\ \text { ERSE } & \text { National energy services regulation entity } \\ \text { EU } & \text { European Union } \\ \text { EV } & \text { Electric vehicle } \\ \text { KPI } & \text { Key performance indicator } \\ \text { PES } & \text { Primary energy supply } \\ \text { PPC } & \text { Peak power contract } \\ \text { PV } & \text { Photovoltaic } \\ \text { RE } & \text { Renewable energy } \\ \text { SES } & \text { Smart energy system } \\ \text { SMILE } & \text { Smart Island Energy system project } \\ \text { TES } & \text { Thermal energy storage } \\ \text { TSO } & \text { Transmission system operator } \\ \text { V2G } & \text { Vehicle to grid }\end{array}$

\section{References}

1. Kang, J.N.; Wei, Y.M.; Liu, L.C.; Han, R.; Yu, B.Y.; Wang, J.W. Energy systems for climate change mitigation: A systematic review. Appl. Energy 2020, 263, 114602. [CrossRef]

2. Marczinkowski, H.M.; Østergaard, P.A.; Djørup, S.R. Transitioning Island Energy Systems—Local Conditions, Development Phases, and Renewable Energy Integration. Energies 2019, 12, 3484. [CrossRef]

3. Scandurra, G.; Romano, A.A.; Ronghi, M.; Carfora, A. On the vulnerability of Small Island Developing States: A dynamic analysis. Ecol. Indic. 2018, 84, 382-392. [CrossRef]

4. Skjølsvold, T.M.; Ryghaug, M.; Throndsen, W. European island imaginaries: Examining the actors, innovations, and renewable energy transitions of 8 islands. Energy Res. Soc. Sci. 2020, 65, 101491. [CrossRef]

5. Kotzebue, J.R.; Weissenbacher, M. The EU's Clean Energy strategy for islands: A policy perspective on Malta's spatial governance in energy transition. Energy Policy 2020, 139, 111361. [CrossRef]

6. Ram, M.; Bogdanov, D.; Aghahosseini, A.; Oyewo, S.; Gulagi, A.; Child, M.; Fell, H.J.; Breyer, C. Global Energy System Based on 100\% Renewable Energy-Power Sector; Lappeenranta: Berlin, Germany, 2017.

7. Hansen, K.; Breyer, C.; Lund, H. Status and perspectives on 100\% renewable energy systems. Energy 2019, 175, 471-480. [CrossRef]

8. Jurasz, J.; Canales, F.A.; Kies, A.; Guezgouz, M.; Beluco, A. A review on the complementarity of renewable energy sources: Concept, metrics, application and future research directions. Sol. Energy 2020, 195, 703-724. [CrossRef]

9. Kuang, Y.; Zhang, Y.; Zhou, B.; Li, C.; Cao, Y.; Li, L. A review of renewable energy utilization in islands. Renew. Sustain. Energy Rev. 2016, 59, 504-513. [CrossRef]

10. Ioannidis, A.; Chalvatzis, K.J.; Li, X.; Notton, G.; Stephanides, P. The case for islands' energy vulnerability: Electricity supply diversity in 44 global islands. Renew. Energy 2019, 143, 440-452. [CrossRef] 
11. Cross, S.; Padfield, D.; Ant-Wuorinen, R.; King, P.; Syri, S. Benchmarking island power systems: Results, challenges, and solutions for long term sustainability. Renew. Sustain. Energy Rev. 2017, 80, 1269-1291. [CrossRef]

12. Meza, C.G.; Zuluaga Rodríguez, C.; D'Aquino, C.A.; Amado, N.B.; Rodrigues, A.; Sauer, I.L. Toward a 100\% renewable island: A case study of Ometepe's energy mix. Renew. Energy 2019, 132, 628-648. [CrossRef]

13. Lund, H. Renewable Energy Systems-A Smart Energy Systems Approach to the Choice and Modeling of 100\% Renewable Solutions, 2nd ed.; Academic Press: Massachusetts, MA, USA; Elsevier: Massachusetts, MA, USA, 2014. [CrossRef]

14. Lund, H.; Andersen, A.N.; Østergaard, P.A.; Mathiesen, B.V.; Connolly, D. From electricity smart grids to smart energy systems-A market operation based approach and understanding. Energy 2012, 42, 96-102. [CrossRef]

15. Sinha, R.; Bak-Jensen, B.; Pillai, J.R.; Zareipour, H. Flexibility from electric boiler and thermal storage for multi energy system interaction. Energies 2019, 13, 98. [CrossRef]

16. Bačeković, I.; Østergaard, P.A. Local smart energy systems and cross-system integration. Energy 2018, 151, 812-825. [CrossRef]

17. Banja, M.; Sikkema, R.; Jégard, M.; Motola, V.; Dallemand, J.-F. Biomass for energy in the EU-The support framework. Energy Policy 2019, 131, 215-228. [CrossRef]

18. Marczinkowski, H.M.; Østergaard, P.A. Evaluation of electricity storage versus thermal storage as part of two different energy planning approaches for the islands Samsø and Orkney. Energy 2019, 175, 505-514. [CrossRef]

19. Alves, M.; Segurado, R.; Costa, M. On the road to $100 \%$ renewable energy systems in isolated islands. Energy 2020, 198, 117321. [CrossRef]

20. Dorotić, H.; Doračić, B.; Dobravec, V.; Pukšec, T.; Krajačić, G.; Duić, N. Integration of transport and energy sectors in island communities with $100 \%$ intermittent renewable energy sources. Renew. Sustain. Energy Rev. 2019, 99, 109-124. [CrossRef]

21. Cabrera, P.; Lund, H.; Carta, J.A. Smart renewable energy penetration strategies on islands: The case of Gran Canaria. Energy 2018, 162, 421-443. [CrossRef]

22. Djørup, S.; Thellufsen, J.Z.; Sorknæs, P. The electricity market in a renewable energy system. Energy 2018, 162, 148-157. [CrossRef]

23. Bublitz, A.; Keles, D.; Zimmermann, F.; Fraunholz, C.; Fichtner, W. A survey on electricity market design: Insights from theory and real-world implementations of capacity remuneration mechanisms. Energy Econ. 2019, 80, 1059-1078. [CrossRef]

24. Sorknæs, P.; Lund, H.; Skov, I.R.; Djørup, S.; Skytte, K.; Morthorst, P.E.; Fausto, F. Smart Energy MarketsFuture electricity, gas and heating markets. Renew. Sustain. Energy Rev. 2020, 119, 109655. [CrossRef]

25. Cuesta, M.A.; Castillo-Calzadilla, T.; Borges, C.E. A critical analysis on hybrid renewable energy modeling tools: An emerging opportunity to include social indicators to optimise systems in small communities. Renew. Sustain. Energy Rev. 2020, 122, 109691. [CrossRef]

26. Brolin, M.; Pihl, H. Design of a local energy market with multiple energy carriers. Int. J. Electr. Power Energy Syst. 2020, 118, 105739. [CrossRef]

27. Hvelplund, F.; Djørup, S. Multilevel policies for radical transition: Governance for a $100 \%$ renewable energy system. Environ. Plan C Polit. Sp. 2017, 35, 1218-1241. [CrossRef]

28. European Commission. Market Legislation: Electricity Market Design. Eur. Comm. Energy Top. 2019. Available online: https://ec.europa.eu/energy/topics/markets-and-consumers/market-legislation/electricitymarket-design_en (accessed on 26 August 2020).

29. Rina Consulting, S.p.A. SMart IsLand Energy Systems Project 2017. Available online: http://www.h2020smile. eu/ (accessed on 20 September 2019).

30. Marczinkowski, H.M. Smart Island Energy Systems Deliverable D8.2; Aalborg University: Aalborg, Denmark, 2018.

31. Leavy, P. Oxford Handbook of Qualitative Research: Oxford Handbook of Qualitative Research; Oxford University Press: Oxford, UK, 2014.

32. Balaman, S..Y.; Balaman, Ş.Y. Uncertainty Issues in Biomass-Based Production Chains. Decis. Biomass-Based Prod. Chain. 2019, 113-142. [CrossRef]

33. ACIF-CCIM. Smart Island Energy Systems Deliverable D4.1; ACIF-CCIM: Funchal, Madeira, 2017.

34. Empresa de Eletricidade da Madeira. EEM 2017 Annual Report; EEM: Funchal, Madeira, 2018. 
35. Lund, P.D.; Lindgren, J.; Mikkola, J.; Salpakari, J. Review of energy system flexibility measures to enable high levels of variable renewable electricity. Renew. Sustain. Energy Rev. 2015, 45, 785-807. [CrossRef]

36. Aalborg University. EnergyPLAN Advanced Energy System Analysis Computer Model; Aalborg University: Aalborg, Denmark, 2017; Available online: https://www.energyplan.eu/ (accessed on 26 August 2020).

37. Vanegas Cantarero, M.M. Reviewing the Nicaraguan transition to a renewable energy system: Why is "business-as-usual" no longer an option? Energy Policy 2018, 120, 580-592. [CrossRef]

38. Lund, H. Large-scale integration of optimal combinations of PV, wind and wave power into the electricity supply. Renew. Energy 2006, 31, 503-515. [CrossRef]

39. Mathiesen, B.V.; Lund, R.S.; Connolly, D.; Ridjan, I.; Nielsen, S. Copenhagen Energy Vision 2050: A Sustainable Vision for Bringing a Capital to 100\% Renewable Energy; Aalborg University: Aalborg, Denmark, 2015.

40. Drysdale, D.; Vad Mathiesen, B.; Lund, H. From Carbon Calculators to Energy System Analysis in Cities. Energies 2019, 12, 2307. [CrossRef]

41. Mathiesen, B.V.; Lund, H.; Connolly, D.; Wenzel, H.; Østergaard, P.A.; Möller, B.; Nielsen, S.; Ridjan, I.; Karnøe, P.; Sperling, K.; et al. Smart Energy Systems for coherent 100\% renewable energy and transport solutions. Appl. Energy 2015, 145, 139-154. [CrossRef]

42. Barros, L.; Barreto, M.; Pereira, L. Understanding the challenges behind Electric Vehicle usage by driversA case study in the Madeira Autonomous Region. In Proceedings of the ICT4S 2020: 7th International Conference on ICT for Sustainability, Bristol, UK, 21-27 June 2020.

43. Hashmi, M.U.; Pereira, L.; Bušić, A. Energy storage in Madeira, Portugal: Co-optimizing for arbitrage, self-sufficiency, peak shaving and energy backup. In Proceedings of the 2019 IEEE Milan PowerTech, Milan, Italy, 23-27 June 2019; pp. 1-15. [CrossRef]

44. República Portuguesa-Ambiente e Ação Climática-Gabinete do Ministro. Incentivo pela Introdução no Consumo de Veículos de Baixas Emissões. Diário Da República no 49/2020, Série II 2020-03-10 Despacho no 3169/2020. 2020. Available online: https://dre.pt/web/guest/pesquisa/-/search/130070443/details/normal?1=1 (accessed on 4 June 2020).

45. Região Autónoma da Madeira-Direção Regional de Economica e Transportes Terrestres. Incentivo à Mobilidade Elétrica na RAM. Funchal, Madeira 2020. Available online: https://www.madeira.gov. pt/drett/Estrutura/Mobilidade/ctl/Read/mid/4064/InformacaoId/54137/UnidadeOrganicaId/17 (accessed on 4 June 2020).

46. Zhao, G.; Nielsen, E.R.; Troncoso, E.; Hyde, K.; Romeo, J.S.; Diderich, M. Life cycle cost analysis: A case study of hydrogen energy application on the Orkney Islands. Int. J. Hydrog. Energy 2018, 44, 9517-9528. [CrossRef]

47. Kwon, Y.; Son, S.; Jang, K. Evaluation of incentive policies for electric vehicles: An experimental study on Jeju Island. Transp. Res. Part A Policy Pract. 2018, 116, 404-412. [CrossRef]

48. Bergaentzlé, C.; Jensen, I.G.; Skytte, K.; Olsen, O.J. Electricity grid tariffs as a tool for flexible energy systems: A Danish case study. Energy Policy 2019, 126, 12-21. [CrossRef]

49. Kalkbrenner, B.J.; Yonezawa, K.; Roosen, J. Consumer preferences for electricity tariffs: Does proximity matter? Energy Policy 2017, 107, 413-424. [CrossRef]

50. Funcke, S.; Ruppert-Winkel, C. Storylines of (de)centralisation: Exploring infrastructure dimensions in the German electricity system. Renew. Sustain. Energy Rev. 2020, 121, 109652. [CrossRef]

51. Specht, J.M.; Madlener, R. Energy Supplier 2.0: A conceptual business model for energy suppliers aggregating flexible distributed assets and policy issues raised. Energy Policy 2019, 135, 110911. [CrossRef]

52. Dutton, S.; Marnay, C.; Feng, W.; Robinson, M.; Mammoli, A. Moore vs. Murphy: Tradeoffs between complexity and reliability in distributed energy system scheduling using software-as-a-service. Appl. Energy 2019, 238, 1126-1137. [CrossRef]

53. Geske, J.; Schumann, D. Willing to participate in vehicle-to-grid (V2G)? Why not! Energy Policy 2018, 120, 392-401. [CrossRef]

(C) 2020 by the authors. Licensee MDPI, Basel, Switzerland. This article is an open access article distributed under the terms and conditions of the Creative Commons Attribution (CC BY) license (http://creativecommons.org/licenses/by/4.0/). 